\title{
Acolhida na disciplina de Prática de Ensino como potencial para diálogos reflexivos para os licenciandos de um curso de Química
}

\author{
Acceptance in the Teaching Practice course as a potential for reflective dialogues for \\ undergraduates of a Chemistry course \\ Aceptación en el curso de Práctica Docente como potencial para diálogos reflexivos para \\ estudiantes de pregrado de un curso de Química
}

Recebido: 08/12/2021 | Revisado: 14/12/2021 | Aceito: 19/12/2021 | Publicado: 03/01/2022

Nairley Cardoso Sá Firmino
ORCID: https://orcid.org/0000-0002-7684-5371
Eniversidade da Integração Internacional da Lusofonia Afro-Brasileira, Brasil
E-mail: nairleysafirmino@ gmail.com
Fábel Franklin de Souza Maia
ORCID: https://orcid.org/0000-0002-3993-5941
E-mail: fabelfranklin @ aluno.unilab.edu.br
Diego Farias Firmino
Universidade da Integração Internacional da Lusofonia Afro-Brasieira, Brasil
ORCID: https://orcid.org/0000-0003-3921-2089
Secretaria de Educação do Ceará, Brasil
E-mail: diego.firmino.ced@ prof.ce.gov.br
Andréa Moura da Costa Souza
ORCID: https://orcid.org/0000-0003-1059-0756
E-mail: andrea.souza@ifce.edu.br
Anna Érika Ferreira Lima
Instituto Federal de Educação, Ciência e Tecnologia do Ceará, Brasil
ORCID: https://orcid.org/0000-0002-8290-9802
E-mail: annaerika@ifá, Brasil
Instituto Federal de Educação, Ciência Tecnologia do Ceá.
Elisangela André da Silva Costa
ORCID: https://orcid.org/0000-0003-0074-1637
E-mail: elisangelaandre@unilab.edu.br
Elcimar Simão Martins
Universidade da Integração Internacional da Lusofonia Afro-Brasileira, Brasil
ORCID: http://orcid.org/0000-0002-5858-5705
E-mail: elcimar@ @unilab.edu.br

\section{Resumo}

Estudantes de cursos de Licenciatura em Química vivenciam uma cultura acadêmica técnica, focada no conhecimento específico, no entanto, ao final da graduação, muitos desses atuarão como professores de Química; em escolas onde o acolhimento é essencial e necessário. Este trabalho tem como objetivo refletir sobre as impressões de licenciandos em Química e o uso de momentos de acolhida na disciplina de Prática de Ensino. Para tanto, foi desenvolvido um estudo de caso, qualitativo e descritivo com 14 estudantes de um curso de Licenciatura em Química do Ceará. Os estudantes consentiram a participação assinando o termo, obedecendo a Resolução no 466/2012. A coleta dos dados foi realizada por meio dos registros de comentários e aplicação de questionário, após a aplicação das acolhidas durante oito encontros no período entre abril e julho de 2021. A análise das respostas demonstrou que $100 \%$ dos estudantes revelaram que as acolhidas foram relevantes para a condução da disciplina, ademais houve expressões de anseios, dúvidas sobre a profissão, compartilhamento de experiências, identificação com situações cotidianas apresentadas. As reflexões que submergiram dos comentários foram elencadas em elementos importantes da prática pedagógica, tais como: motivação, características do ensino e aprendizagem, inovação no ensino, planejamento, o papel das disciplinas pedagógicas na formação docente, o processo dialógico também proporcionado pela identificação de conhecimentos prévios dos estudantes, a superação dos desafios na formação docente. Portanto, pode-se concluir que as acolhidas proporcionaram reflexões acerca da profissão e suas implicações fortalecendo uma identificação dos licenciandos como futuros educadores químicos.

Palavras-chave: Acolhida; Formação inicial; Reflexões; Professores de química. 


\begin{abstract}
Chemistry undergraduate students experience a technical academic culture, focused on specific knowledge, however, at the end of graduation, many of them will act as Chemistry teachers in schools where welcoming is essential and necessary. This work aims to reflect on the impressions of undergraduates in Chemistry on the use of moments of welcome in the subject of Teaching Practice. For that, a qualitative and descriptive case study was developed with 14 students of a Licentiate Degree in Chemistry in Ceará. Students consented to participate by signing the term, in compliance with Resolution 466/2012. Data collection was carried out through the records of comments and questionnaire application, after the application of the welcomes during eight meetings between April and July 2021. The analysis of the responses showed that $100 \%$ of the students revealed that the welcomes were relevant for the conduct of the discipline, there were also expressions of anxieties, doubts about the profession, sharing of experiences, identification with everyday situations presented. The reflections that submerged from the comments were listed in important elements of pedagogical practice, such as: motivation, teaching and learning characteristics, teaching innovation, planning, the role of pedagogical subjects in teacher education, the dialogical process also provided by the identification of knowledge students', overcoming the challenges in teacher training. Therefore, it can be concluded that the receptions provided reflections on the profession and its implications, strengthening an identification of the undergraduates as future chemical educators.
\end{abstract}

Keywords: Welcome; Initial formation; Reflections; Chemistry teachers.

\title{
Resumen
}

Los estudiantes de licenciatura en Química experimentan una cultura académica técnica, enfocada en conocimientos específicos, sin embargo, al finalizar la graduación, muchos de ellos actuarán como profesores de Química en escuelas donde la acogida es fundamental y necesaria. Este trabajo tiene como objetivo reflexionar sobre las impresiones de los licenciados en Química sobre el aprovechamiento de los momentos de acogida en la asignatura de Práctica Docente. Para ello, se desarrolló un caso de estudio cualitativo y descriptivo con 14 estudiantes de la Licenciatura en Química en Ceará. Los estudiantes dieron su consentimiento para participar mediante la firma del plazo, en cumplimiento de la Resolución 466/2012. La recolección de datos se realizó a través de los registros de comentarios y aplicación de cuestionarios, luego de la aplicación de las bienvenidas durante ocho reuniones entre abril y julio de 2021. El análisis de las respuestas arrojó que el 100\% de los estudiantes reveló que las bienvenidas fueron relevantes para la conducta. de la disciplina, también hubo expresiones de ansiedades, dudas sobre la profesión, intercambio de experiencias, identificación con situaciones cotidianas presentadas. Las reflexiones que se sumergieron a partir de los comentarios se enumeraron en elementos importantes de la práctica pedagógica, tales como: motivación, características de enseñanza y aprendizaje, innovación docente, planificación, el rol de los sujetos pedagógicos en la formación del profesorado, el proceso dialógico también provisto por la identificación de saberes. estudiantes ', superando los retos en la formación del profesorado. Por lo tanto, se puede concluir que las recepciones brindaron reflexiones sobre la profesión y sus implicaciones, fortaleciendo una identificación de los estudiantes de pregrado como futuros educadores químicos.

Palabras clave: Bienvenidos; Formación inicial; Reflexiones; Profesores de química.

\section{Introdução}

Em cursos de licenciaturas em ciências exatas existe uma imagem de dureza, na qual se preconiza um distanciamento nas relações entre professores e estudantes. Esta visão foi construída ao longo dos anos, fruto do ensino fortemente baseado na racionalidade técnica (Maldaner, 2008) e, nestes moldes, o bom estudante é aquele com habilidade de resolver questões e reproduzir conceitos prontos. Tais comportamentos são característicos de professores com formação inicial em cursos de bacharelado, embora isso não seja de modo algum uma regra, pois sempre há de se considerar as individualidades dos profissionais.

O currículo dos cursos de licenciatura em química segue um modelo segmentado em disciplinas específicas, denominadas de cunho científico, e as pedagógicas. Segundo as ideações de Mourão e Guedin (2019), o esquema $3+1$ causa impactos até os dias atuais, mesmo com as mudanças ocorridas na legislação ao longo dos anos e a ampliação de carga horária prática. Deste modo, os licenciandos vivem essa dicotomia, observando muitas vezes os professores que tanto admiram pelo domínio do conhecimento químico, menosprezando a relevância das disciplinas pedagógicas. Os estudantes, consequentemente, mesmo em curso de formação de professores, visualizam concluir a graduação e atuar em espaços de pesquisa, bem como em instituições com âmbitos laboratoriais. 
Os cursos de Licenciatura em Química, no entanto, têm como principal objetivo formar professores para atuarem na Educação Básica. Oliveira et al. (2017) nos convidam a pensarmos em currículos que contemplem a formação específica, mas principalmente, a formação pedagógica do futuro professor. Nessa direção, as Diretrizes Curriculares Nacionais para a Formação Inicial de Professores para a Educação Básica (2019) discriminam como competência geral docente o exercício de elementos essenciais para a resolução de conflitos, promoção do respeito com acolhimento, sem preconceitos, em busca de desenvolver um recinto colaborativo nos ambientes de aprendizagem.

Posto isto, verifica-se que o acolhimento, tão característico dos espaços escolares, lócus de atuação da maior parte dos graduados nos cursos de licenciatura, não é comumente vivenciado na universidade. Quando lançamos olhares para o Ensino Superior, percebemos de maneira mais evidente que tais momentos direcionados ao acolhimento se tornam ausentes. Evidenciamos assim, a ausência dos espaços de acolhimento quando estamos na posição de estudante e muitas vezes sem nos darmos conta, reproduzimos as mesmas atitudes quando estamos na condição de docente. Contudo, oportunizar a realização de tais momentos pode contribuir na melhoria das demais atividades que serão desenvolvidas ao longo do processo educacional.

Concordamos com Rodrigues (2001) quando afirma que a responsabilidade da educação é social. Assim, compreendemos que a formação integral do homem deve ser encarada como objetivo de todos os níveis de ensino, inclusive o superior, e isto só acontece quando os alunos são compreendidos de maneira completa e integral, respeitando suas características individuais, tanto pessoais quanto acadêmicas. Daí o sentido da afirmação: "Razão e sensibilidade deveriam, portanto, caminhar juntas recriando o homem em todas as suas potencialidades e libertando-o das exclusivas determinações da razão" (Goergen, 2016, p. 65).

Nesse sentido, nas universidades, os docentes assumem papel importantíssimos tornando os espaços acadêmicos locais favoráveis à formação completa dos discentes, e que as salas de aula se tornem ambientes acolhedores, pois o meio acadêmico, mesmo que se apresentando como um local complexo, possa contribuir positivamente na vida universitária dos discentes, possibilitando uma fase especial marcada de sentidos afetivos e significativos, onde na práxis docente contribua para uma vivência com aspectos intelectuais, mas também repletos de sentimentos e emoções.

Compreendemos que o aspecto afetivo que o autor apresenta diz respeito ao trabalho do professor com o educando, e que envolve de significado o aspecto humano existente entre professor e aluno. Os sentimentos de afetividade, parceria, união, respeito quando expressados pelo professor para com os alunos, pode auxiliar positivamente no desenvolvimento educacional do educando. Para uma melhor compreensão, podemos refletir novamente no pensamento de Freire (2011, p. 138) que diz: "[...] a afetividade não se acha excluída da cognoscibilidade". Faz-se necessário que o professor crie com o aluno um laço afetivo harmonioso. Esse bom relacionamento sem dúvida trará aspectos positivos nas suas aulas e facilitará alcançar os objetivos desejados na aprendizagem.

É importante destacar que na maioria das vezes as atividades que são desenvolvidas dentro da sala de aula se pautam apenas na mera transmissão de conhecimento, numa relação completamente técnica, distanciando os envolvidos no processo ensino aprendizagem. Por outro lado, é preciso reinsistir em que não se pense que a prática educativa vivida com afetividade e alegria prescinda da formação científica séria e da clareza política dos educadores ou educadoras. A prática educativa é tudo isso: afetividade, alegria, capacidade científica, domínio técnico a serviço da mudança ou, lamentavelmente, da permanência do hoje (Freire, 2011). Nos espaços educacionais, as relações deveriam ser de troca de experiências, partilhas, amizades; minimizando assim as dificuldades e possibilitando aprendizados significativos.

Para Goergen (2016), um dos grandes desafios da educação contemporânea é conseguir equilibrar a formação teórica com a formação humana. Exclusivamente esse equilíbrio tem seguido na direção de uma formação totalmente técnica, direcionada ao mercado de trabalho. Claramente entendemos que esse movimento não deixa de estar de acordo com a 
formação humana, visto que toda ação laboral está intrinsecamente ligada ao cotidiano das pessoas, porém não pode ficar somente no contexto técnico, precisa se direcionar também às outras dimensões das atividades humanas.

Ao transitar pelas esferas da Educação Básica e Ensino Superior, ponderemos sobre uma outra perspectiva: os desafios nas transições e adaptações na vida estudantil, pois uma nova realidade educacional exigirá outros comportamentos e atitudes. Deste modo, salienta-se a afirmação de Freire (1979, p.18): "Não há transição que não implique um ponto de partida, um processo e um ponto de chegada. Todo amanhã se cria num ontem, através de um hoje. De modo que o nosso futuro se baseia no passado e se corporifica no presente. Temos de saber o que fomos e o que somos, para sabermos o que seremos." Quando refletimos sobre essa transição e a trajetória do estudante na universidade, percebemos uma complexidade, pois para alguns não se apresenta uma passagem tranquila, onde o discente consegue se adaptar com tanta facilidade.

Coulon (2008) trata essa transição do ensino médio para o ensino superior como delicada, logo responsável pelos maiores índices de fracasso ao longo do primeiro ciclo. Segundo o autor, a ligação entre o ensino médio e o ensino superior pode ser denominada como "processos de passagem" apresentando três fases desta transição à condição de estudante. São elas: o tempo de estranhamento, onde ocorre a separação em relação ao status passado; o tempo de aprendizagem, que se constitui numa fase de constantes ambiguidades e o tempo de afiliação, fase de conversão, admissão no ambiente acadêmico.

Por conseguinte, compreendemos a utilização de estratégias de acolhimento como uma maneira de facilitar a adaptação dos estudantes ao ensino superior. No movimento de adaptação, estranhamento e afiliação no contexto da universidade, refletimos sobre as relações que se estabelecem dentro dos ambientes universitários, sobretudo na sala de aula, pois os vínculos ali formados podem fortalecer os processos pedagógicos contribuindo para a formação integral dos discentes.

De acordo com Coulon (2008) a dimensão do acolhimento - sobretudo a falta dele - é ressaltada como um dos aspectos que reforçam uma sensação de impotência, falta de motivação e dificuldades aparentemente intransponíveis que acometem parte considerável dos estudantes. Conforme o autor, o acolhimento nos espaços educacionais é amplo e significativo para todos os sujeitos envolvidos no processo de aprendizagem, tanto para se construir a relação com o meio social quanto às interações que ocorrem nele. Nesse sentido, as instituições, por meio da ação docente, precisam perceber a importância do acolhimento aos discentes nos processos formativos, devendo promover o bem estar dos mesmos durante as aulas, onde o aluno sinta-se acolhido e desperte nele o sentimento de pertencimento ao lugar que está inserido, sendo possível o desenvolvimento de novas habilidades, saberes e aprendizados.

Isto posto, aliado ao contexto dos cursos de Licenciatura em Química, é possível vislumbrar a relevância da inserção desta temática a tais estudantes. Ao vivenciar estratégias de acolhimento na universidade, os graduandos poderão se beneficiar na adaptação e desenvolvimento nas disciplinas durante o curso, bem como os futuros professores de Química poderão mais facilmente aplicá-las na sua prática pedagógica quando for o momento. Tal situação pode ser percebida na reflexão de Guimarães e Boruchovitch (2004) que compreende a universidade como sendo um espaço de aprendizagem e de socialização, devendo favorecer tanto o desenvolvimento cognitivo quanto o afetivo. Nessa direção, o seguinte trabalho objetivou refletir sobre as impressões de licenciandos em Química sobre o uso de momentos de acolhida na disciplina de Prática de Ensino.

\section{Metodologia}

O estudo desenvolvido se pautou na pesquisa de abordagem qualitativa, com objetivos da pesquisa exploratória por meio de estudo de caso. Nesse sentido, Minayo (2001), sinaliza que a pesquisa qualitativa trabalha com o universo de significados, motivos, aspirações, crenças, valores e atitudes, o que corresponde a um espaço mais profundo das relações, dos processos e dos fenômenos que não podem ser reduzidos à operacionalização de variáveis. 
A pesquisa exploratória proporciona uma maior familiaridade sobre o objeto de estudo, ou seja, o problema ainda não está totalmente definido. Assim, a exploração torna o tema mais explícito, facilitando a construção de hipóteses (Prodanov \& Freitas, 2013). Já o estudo de caso busca compreender um fenômeno em sua profundidade, especialmente quando os limites com o contexto não são claramente evidentes (Yin, 2015). Nessa perspectiva, acreditamos que as reflexões surgidas durante todo o percurso metodológico nos permitiu alcançar resultados claros e objetivos, possibilitando maior apropriação e aproximação de todos os processos e resultados que foram obtidos, além da garantia de toda uma riqueza de significados.

Assim, o estudo foi desenvolvido com 14 discentes, devidamente matriculados na disciplina de Prática de Ensino de um Curso de Licenciatura em Química do Ceará. A disciplina foi ministrada entre os dias 07 de abril e 28 de julho de 2021. É importante destacar que todos os estudantes preencheram o Termo de Consentimento Livre e Esclarecido (TCLE) e os aspectos éticos foram respeitados de acordo com a resolução No 466, DE 12 DE DEZEMBRO DE 2012.

$\mathrm{Na}$ intenção de colher os relatos dos licenciandos do curso de Química, após a aplicação de cada momento de acolhida, os depoimentos dos estudantes foram gravados. Ao final do semestre, os estudantes responderam um questionário, aplicado por meio da interface Google Forms, no qual registraram suas impressões sobre a utilização das acolhidas e a implicação desta estratégia para o desenvolvimento da disciplina.

Durante o semestre, houve 12 encontros com os estudantes, os quais ocorreram da seguinte forma: o primeiro para apresentação da disciplina, da proposta de execução da pesquisa, dos métodos avaliativos, entre outros pontos; três encontros foram destinados às avaliações e oito encontros com atividades teóricas e práticas. Nestes oito encontros seguiu-se o ritual: acolhida, explicação teórica expositiva do conteúdo, metodologia ativa ou atividade prática, avaliação formativa.

A seleção das acolhidas foi realizada com critérios que variaram desde a correlação com o conteúdo a ser ministrado naquela aula, até situações vivenciadas pelos estudantes que impactavam diretamente na relação com a profissão. As acolhidas utilizadas foram:

01. Charge sobre aulas remotas. Instagram: @escoladepassarinhos

02. Texto: "Aprendendo Professorando"

03. Conto Hindu: Os cegos e o elefante

04. Imagens relacionadas com o tema: "O ensino e a aprendizagem"

05. Música: "Deus me proteja de mim" de Chico César

06. Texto: "Persistência é resistência"

07. Texto: "Professora Cici Entista no planejamento"

08. Texto: "Ausências e superações

Na realização de cada um dos oito encontros houve o convite para os participantes compartilharem suas impressões sobre as temáticas abordadas nos momentos de acolhimento e as experiências na sua trajetória acadêmica e/ou profissional. A análise iniciou a partir do convite e o registro da participação dos discentes e suas percepções na busca por identificar pontos em comum nas respostas, as escolhas dos diálogos dos textos no artigo foi aleatória, seguindo o critério de aproximação dos relatos com a realidade vivenciada com convergência para os diálogos reflexivos sobre a prática de ensino de química.

\section{Resultados e Discussão}

A utilização de acolhidas em cursos de ciências exatas não é algo comum, no entanto, a experiência vivenciada pelos estudantes demonstrou uma aceitabilidade quanto à estratégia. Devido a prática ser incomum, houve uma certa resistência à 
participação nos primeiros encontros, mas com o passar dos dias, a familiaridade aumentou o envolvimento dos estudantes. Tal realidade foi percebida nos resultados obtidos com a aplicação do questionário, no qual 100\% dos estudantes revelaram que as acolhidas foram relevantes na condução da disciplina.

De um modo geral, em todos os momentos de acolhida os estudantes teceram comentários, se envolveram e compartilharam sentimentos. O exercício das reflexões acerca da própria profissão foi observado a partir de relatos como este: "Em uma certa acolhida fiquei pensativo no futuro de ser professor, tinha muitas dúvidas que foram respondidas nela, fiquei com algumas ainda, mas fiquei bem motivado e esperançoso para exercer a profissão" (Respondente X). A partir deste comentário e o contexto da estrutura do curso, é possível perceber o alcance da reflexão, pois traz a formação de uma identidade docente.

Um dos agravos do currículo fortemente influenciado pelo modelo $3+1$ nas licenciaturas é a dificuldade de identificação com a profissão de professor. A dicotomia disciplinas específicas e pedagógicas de modo que não se interrelacionam, associado a professores que aparentemente colocam a docência, ou os conhecimentos da didática envolvida no ensino de Química, como algo de menor status contribuem para esse cenário (Mourão \& Ghedin, 2019).

Ademais, os estudantes expressaram que: "As acolhidas foram muito importantes pois a partir delas a gente entrou no conteúdo de forma leve e fez a gente participar da aula" (Respondente Y); "[...] as acolhidas sempre me causaram impacto, era uma forma da professora 'quebrar o gelo' antes de introduzir o conteúdo" (Respondente Z); "Até o momento nesses meus 3 anos de graduação essa disciplina foi a $1^{a}$ que teve acolhida, e gostei muito, todas as acolhidas foram importantes" (Respondente A). A receptividade com os momentos de acolhida foi crescendo ao longo dos encontros, inclusive ao justificar o atraso para chegar em uma das aulas, um estudante lamentou, pois segundo ele: "[...] vou perder a acolhida, a melhor parte da aula" (Respondente K).

A aceitabilidade das acolhidas pelos discentes revelou o quanto esses momentos proporcionaram reflexões acerca da profissão e aberturas para fortalecimento das relações aluno-professor. Apesar das iniciais resistências, os espaços educacionais possibilitam essa construção, facilitando a aquisição de conhecimento e a interlocução entre os pares. Freire (1979, p. 162-163), enfatiza que “[...] não importa com que faixa etária trabalhe o educador ou a educadora, não importa em qual etapa da formação essas relações aconteçam, o mais importante é que elas se tornem permanentes, possibilitando o pleno desenvolvimento dos educandos."

Nesse sentido, autores como Larossa (2002), Guimarães e Boruchovitch (2004), Tomaél, Alcará e Chiara (2005) e Freire (2011), nos convidam a refletir sobre a importância da ação docente que perpassa pelas dimensões pessoais e profissionais contribuindo para a construção de saberes significativos, os quais refletem o verdadeiro sentido de aprender novos conhecimentos. Neste esteio, a construção de novos aprendizados permeia um espaço onde todos se sentem responsáveis por esse processo, pois o sucesso do aluno é reflexo de grande parte do que aprendeu na sala de aula. Essa corresponsabilidade coloca o professor e o aluno na condição de protagonistas do saber, onde ambos aprendem e crescem juntos.

A relação professor-aluno é essencialmente relevante para a trajetória universitária, isso tem uma grande contribuição do modus operandi, impressa pelo professor na sala de aula, priorizando empatia, diálogo, capacidade de escutar, observar as inquietações e dificuldade dos estudantes, experienciar a troca, a convivência leve e saudável. Ademais, o elo entre professor e aluno marca o desenvolvimento dos discentes, pois influencia além da transmissão de conteúdos. Os docentes universitários são vistos como referenciais, portanto, despertam certa expectativa nos estudantes, os quais contam ter o apoio daquele profissional diante das dificuldades, sejam elas de natureza cognitiva, pessoal e até em momentos de conflitos (Ribeiro, 2020).

Ao considerar as impressões expressas pelos estudantes acerca das acolhidas de um modo geral, os relatos demonstraram profundas reflexões sobre o ser professor, o futuro que os aguarda, no entanto, de modo implícito, diz muito sobre as relações com os professores formadores, pertencentes ao curso de licenciatura. Sobre o professor do ensino superior, 
Santana e Ribeiro (2021) trazem a figura deste docente inserido na conjuntura política e social da educação superior, pois existem aspectos ideológicos e pragmáticos, os quais nem sempre são compatíveis com os seus próprios valores acerca do ensino e educação. Ademais, na busca por uma reflexão sobre uma pedagogia universitária, os autores Teixeira, Bernini e Santos (2018) levantam questionamentos sobre a qualidade do conhecimento produzido e disseminado nas universidades, a condução dos processos educativos e a formação de profissionais para atuar na sociedade.

Muitos professores das licenciaturas em Química têm sua formação inicial em cursos de bacharelado ou engenharias, nos quais as relações educativas, especialmente aquelas voltadas ao campo afetivo, não compõem o campo de saberes desses profissionais. Esses professores, atuando em cursos voltados para a formação de professores, apresentam comportamentos diversos, dentre os quais podemos citar alguns que buscam se especializar e se dedicam a conhecer os elementos da prática educativa e outros que ignoram o objetivo do curso e trazem o conhecimento específico puro, incentivando a pesquisa científica desvinculada do ensino. A influência não é apenas observada no âmbito de elementos essenciais do trabalho docente como planejamento, avaliação, didática etc. As relações, especialmente no que diz respeito ao diálogo, a troca de experiências e a afetividade, entre professores e estudantes também são afetadas.

A aquisição do conhecimento específico das ciências também é influenciada pelas relações pedagógicas, segundo Quadros, Silva e Mortimer (2018) há o reconhecimento da importância dos aspectos afetivos e emocionais nas pesquisas na área de ensino de Ciências, pois interferem nas atitudes que os estudantes têm a respeito da Ciência. Portanto, os autores indicam alguns exemplos de atitudes capazes de aproximar estes atores no processo educacional, como o respeito ao ponto de vista do estudante, a escuta acerca de sua compreensão sobre um fenômeno. Os resultados deste estudo demonstram o potencial da utilização dos momentos de acolhida como espaços de aproximação, de escuta, de trocas de experiências, os quais podem facilitar a aprendizagem.

Nessa direção, vale ressaltar os processos de passagem tratados por Coulon (2008), reiterando as influências nas adaptações aos níveis de ensino. Ademais, há de se considerar as caraterísticas do conhecimento no ensino superior, pois são mais especializados, exigem a compreensão de termos técnicos cuja utilização exige preparação dos indivíduos, de modo prático e racional, nas áreas pautadas pela Ciência e Tecnologia (Quadros, Silva \& Mortimer, 2018). No caso dos futuros professores, os processos de passagem entre os níveis do ensino básico e superior ocorrem no ingresso às licenciaturas e no início da atividade profissional, em atuação como docentes na Educação Básica. Acredita-se que quanto mais os licenciandos vivenciarem as estratégias da prática pedagógica nos cursos de formação inicial, a adaptação e o desempenho como profissional tendem a ser facilitados.

A aplicação das acolhidas ocorreu considerando objetivos de aprendizagem ou circunstâncias impactantes na atividade docente e discente. O Quadro 1 traz a descrição das acolhidas, seus objetivos e, principalmente, as reflexões que surgiram após sua utilização. 
Quadro 1 - Caracterização das acolhidas e as reflexões que submergiram dos comentários dos licenciandos de Química.

\begin{tabular}{|c|c|c|c|}
\hline Encontro & Objetivo da acolhida & Descrição da acolhida & Reflexões \\
\hline $\begin{array}{l}\mathbf{0 1} \\
\text { Charge sobre aulas } \\
\text { remotas. Instagram: } \\
\text { @escoladepassarinhos }\end{array}$ & $\begin{array}{l}\text { Possibilitar reflexões sobre } \\
\text { os desafios e superações do } \\
\text { ensino remoto, mais } \\
\text { especificamente sobre a } \\
\text { disciplina ministrada. }\end{array}$ & $\begin{array}{l}\text { A charge discute sobre o ensino } \\
\text { remoto e incita uma discussão } \\
\text { sobre as potencialidades e } \\
\text { desafios no desenvolvimento da } \\
\text { disciplina neste formato. }\end{array}$ & $\begin{array}{l}\text { Compreensão sobre as } \\
\text { diferentes possibilidades de } \\
\text { inovações e estratégias no } \\
\text { ensino frente aos desafios } \\
\text { impostos pela pandemia. }\end{array}$ \\
\hline $\begin{array}{l}\mathbf{0 2} \\
\text { Texto: "Aprendendo } \\
\text { Professorando" de } \\
\text { autoria da professora }\end{array}$ & $\begin{array}{l}\text { Refletir sobre a importância } \\
\text { da disciplinas pedagógicas } \\
\text { na formação docente, } \\
\text { inclusive para estudantes } \\
\text { que já atuam como } \\
\text { professores }\end{array}$ & $\begin{array}{l}\text { O texto narrativo conta a história } \\
\text { de uma professora ainda } \\
\text { licencianda que concilia os } \\
\text { aprendizados da profissão com os } \\
\text { desafios da graduação. }\end{array}$ & $\begin{array}{l}\text { As disciplinas pedagógicas na } \\
\text { formação docente contribuem } \\
\text { significativamente para o } \\
\text { processo de reflexão-ação- } \\
\text { reflexão da prática } \\
\text { pedagógica. }\end{array}$ \\
\hline $\begin{array}{l}\mathbf{0 3} \\
\text { Conto Hindu: Os } \\
\text { cegos e o elefante }\end{array}$ & $\begin{array}{l}\text { Proporcionar diálogos } \\
\text { reflexivos sobre a } \\
\text { importância do docente } \\
\text { considerar as aprendizagens } \\
\text { que cada discente possui } \\
\text { sobre determinado assunto. }\end{array}$ & $\begin{array}{l}\text { A história mostra as diferentes } \\
\text { interpretações dos cegos sobre o } \\
\text { elefante, os diferentes pontos de } \\
\text { vista sobre algo. }\end{array}$ & $\begin{array}{l}\text { Respeitar e valorizar os } \\
\text { conhecimentos que os } \\
\text { discentes possuem a partir do } \\
\text { ponto de vista que possuem } \\
\text { previamente sobre alguns } \\
\text { conteúdos. }\end{array}$ \\
\hline $\begin{array}{l}\mathbf{0 4} \\
\text { Imagens relacionadas } \\
\text { com o tema: "O } \\
\text { ensino e a } \\
\text { aprendizagem" }\end{array}$ & $\begin{array}{l}\text { Analisar as características } \\
\text { do ensino, aprendizagem e o } \\
\text { papel do professor na } \\
\text { relação estabelecida dentro } \\
\text { do processo educacional. }\end{array}$ & $\begin{array}{l}\text { Sequência de imagens sobre as } \\
\text { características do ensino, } \\
\text { aprendizagem e condição do } \\
\text { professor nesse intermédio. }\end{array}$ & $\begin{array}{l}\text { As características do ensino e } \\
\text { da aprendizagem se } \\
\text { complementam no movimento } \\
\text { dialógico conduzido pelo } \\
\text { professor. }\end{array}$ \\
\hline $\begin{array}{l}\mathbf{0 5} \\
\text { Música: "Deus me } \\
\text { proteja de mim" de } \\
\text { Chico César }\end{array}$ & $\begin{array}{l}\text { Dialogar sobre os impactos } \\
\text { positivos e negativos } \\
\text { ocasionados pela pandemia } \\
\text { na vida pessoal e } \\
\text { profissional dos docentes. }\end{array}$ & $\begin{array}{l}\text { A escolha dessa música ocorreu } \\
\text { pelas circunstâncias vivenciadas } \\
\text { na pandemia e os impactos na } \\
\text { vida, principalmente na saúde } \\
\text { mental de todos. }\end{array}$ & $\begin{array}{l}\text { O cuidado com a saúde, } \\
\text { principalmente a saúde mental } \\
\text { no período de pandemia é } \\
\text { fator primordial para o bom } \\
\text { desempenho profissional dos } \\
\text { docentes. }\end{array}$ \\
\hline $\begin{array}{l}\mathbf{0 6} \\
\text { Texto: "Persistência é } \\
\text { resistência" de autoria } \\
\text { da professora }\end{array}$ & $\begin{array}{l}\text { Despertar nos discentes os } \\
\text { sentimentos de confiança, } \\
\text { superação e coragem diante } \\
\text { dos desafios no exercício da } \\
\text { profissão docente. }\end{array}$ & $\begin{array}{l}\text { O texto narra as circunstâncias } \\
\text { que os estudantes vivenciam } \\
\text { quanto às incertezas diante do } \\
\text { contexto do país, das condições de } \\
\text { trabalho dos professores. }\end{array}$ & $\begin{array}{l}\text { As contribuições apresentadas } \\
\text { pelos discentes trouxeram } \\
\text { aspectos de motivação mesmo } \\
\text { diante das dificuldades em } \\
\text { exercer a profissão. }\end{array}$ \\
\hline $\begin{array}{l}\mathbf{0 7} \\
\text { Texto: "Professora } \\
\text { Cici Entista no } \\
\text { planejamento" de } \\
\text { autoria da professora }\end{array}$ & $\begin{array}{l}\text { Compreender o papel do } \\
\text { planejamento } \\
\text { desenvolvimento no } \\
\text { trabalho do professor de } \\
\text { Ciências e como fazê-lo } \\
\text { diante das peculiaridades da } \\
\text { rotina escolar }\end{array}$ & $\begin{array}{l}\text { O texto narra a personagem Cici } \\
\text { Entista buscando realizar o } \\
\text { planejamento de uma aula de } \\
\text { Ciências num cenário onde todos } \\
\text { os recursos estavam disponíveis, } \\
\text { no entanto, enfatizando as } \\
\text { dificuldades com a rotina escolar. }\end{array}$ & $\begin{array}{l}\text { A compreensão sobre a } \\
\text { importância do planejamento } \\
\text { no desenvolvimento da prática } \\
\text { pedagógica frente às } \\
\text { especificidades do trabalho } \\
\text { docente do professor de } \\
\text { ciências. }\end{array}$ \\
\hline $\begin{array}{l}\mathbf{0 8} \\
\text { Texto: "Ausências e } \\
\text { superações" de autoria } \\
\text { da professora }\end{array}$ & $\begin{array}{l}\text { Incentivar a busca pela } \\
\text { formação docente, mesmo } \\
\text { com as dificuldades } \\
\text { evidenciadas nos cursos de } \\
\text { Licenciatura em Química }\end{array}$ & $\begin{array}{l}\text { O texto conta a trajetória de uma } \\
\text { professora de Química onde são } \\
\text { descritas ausências que implicam } \\
\text { em impactos na formação } \\
\text { docente, consequentemente } \\
\text { precisam ser superadas. }\end{array}$ & $\begin{array}{l}\text { As percepções apresentadas } \\
\text { pelos discentes refletiram a } \\
\text { importância da busca por uma } \\
\text { formação docente mesmo que } \\
\text { repleta de desafios, mas que } \\
\text { precisam ser superados. }\end{array}$ \\
\hline
\end{tabular}

Fonte: Autores (2021).

A partir das reflexões dispostas no Quadro 1 identificamos alguns elementos essenciais, os quais devem estar 
presentes na prática pedagógica. Alguns desses implicam fortemente no bom desempenho do trabalho docente, tais como: motivação, características do ensino e aprendizagem, inovação no ensino, planejamento, o papel das disciplinas pedagógicas na formação docente, o processo dialógico proporcionado pela identificação de conhecimentos prévios dos estudantes, a superação dos desafios na formação docente. As reflexões resultantes desses momentos são valiosas, a considerar um público com pouca identificação com a profissão de professor, ainda mais aqueles influenciados pelos próprios docentes com caráter mais técnico.

Por conseguinte, verificou-se que algumas acolhidas marcaram mais profundamente os estudantes. São elas:

\section{- $\quad$ Acolhida 02}

O texto: "Aprendendo Professorando" traz a narrativa de uma licencianda já atuando como docente, as descrições da rotina e das aprendizagens acerca da profissão proporcionaram reflexões. Sobre esse texto, um estudante comentou: "Na primeira aula (que participei), a professora fazia a leitura de um texto onde detalhou um pouco sobre a rotina cansativa de uma aluna que tentava, com muito esforço, conciliar a graduação e um trabalho recém-conseguido de professora. Achei o texto bem profundo, uma vez que consegui me enxergar na personagem, assim como uma parte dos alunos, pois é a realidade de muitos estudantes de licenciatura. Ao final da leitura e reflexão, descobrimos que o texto era de autoria da professora, sendo ela narradora/personagem" (Respondente J).

Além disso, em um comentário após a acolhida uma estudante relatou: “[...] acho que ela está falando de mim, [...] é exatamente assim, [...] esse texto é muito real, acredito que quem fez estava nesse momento de estar conciliando os dois períodos. Nós como estudantes, muito amadores nessa área, temos aquela ansiedade de entrar na sala de aula. A gente acha que por saber os conceitos básicos vai conseguir ter o controle de uma turma, ao passo que os dias vão passando e os conteúdos vão aparecendo você percebe que não é tão bom assim [...]. O aluno, agora com a visão de professor, vai tentar adquirir uma postura que ele ainda não tem, pois nós não temos essa postura de professores, somos estudantes com o mínimo de conhecimento para já estar exercendo a profissão."

\section{- $\quad$ Acolhida 05}

Em um momento fortemente impactado pelos acontecimentos da pandemia, os estudantes estavam desmotivados e entristecidos, então houve a utilização da música: "Deus me proteja de mim" do cantor Chico Cesar. Sobre esse acontecimento, os estudantes escreveram: "As acolhidas em geral, foram muito bem conduzidas na disciplina. Uma delas em especial, que teve um impacto para mim, foi com a música do Chico César que se chama Deus me Proteja. É uma música linda, em que tive muitas reflexões importantes para a vida, para a disciplina e para o curso de Química." (Respondente Q). "Quando a professora tirou um tempo [...] para falar sobre o atual momento de pandemia que estamos vivendo. Falando sobre saúde mental, os problemas que todos nós enfrentamos no dia a dia e que é normal, todos passamos por isso. Ali eu percebi que não estava sozinho e que todo mundo passa por momentos de incertezas." (Respondente S).

\section{- $\quad$ Acolhida 07}

A utilização de uma história com uma personagem fictícia, a Cici Entista, e apresentando condições que variavam entre elementos reais e utópicos também repercutiu positivamente. O texto: "A professora Cici Entista no planejamento" promoveu reflexões, inclusive com observações contundentes sobre as condições estruturais das escolas, pois todos os recursos dos quais ela necessitava estavam disponíveis. Além disso, os estudantes identificaram outros aspectos que interferem no planejamento escolar, tais como: solicitações da gestão no horário do planejamento, realização de atividades do trabalho na residência, as dificuldades dos professores nas diversificações das aulas nas escolas. Este comentário revela os 
questionamentos: "Sobre a Cici, pude me imaginar na personagem com tantos desgastes na vida, mas ainda assim acreditava que podia fazer diferente na próxima, me imaginei se teria a mesma autoestima dela no futuro ou se cairia no tradicionalismo." (Respondente R).

As reflexões envoltas na aplicação das acolhidas são significativas, sobretudo porque abrangem diversos elementos relevantes para discussão. Podemos inferir sobre características peculiares dos cursos de licenciatura, iniciando pela influência do modelo da racionalidade técnica no currículo, e até no modo de pensar dos graduandos.

É preciso compreender o perfil dos estudantes das licenciaturas em Química, pois uma grande maioria entra no curso sem refletir profundamente que atuarão como professores. Os cursos de licenciatura geralmente são noturnos, fator facilitador para aqueles que trabalham, então muitos graduandos são trabalhadores, acarretando em menos tempo de dedicação aos estudos. Ademais, geralmente estes estudantes se identificam com as ciências exatas no sentido também da lógica, da objetividade e da técnica, por sua vez estão mais interessados nos fenômenos do que nas relações humanas. Ao longo do curso, encontram mais alguns desafios que contribuem para o fortalecimento dessa visão, como os professores formadores supervalorizando o conhecimento químico em detrimento do pedagógico, poucos docentes das disciplinas pedagógicas com formação inicial na área de química e, por isso, desconhecem esse universo, portanto passam por dificuldades para impetrar um discurso dialógico interessante associando os contextos.

Um estudo realizado por Gonçalves e Fernandes (2010) trouxe algumas discussões acerca da influência da racionalidade técnica na formação inicial, uma destas é a valorização desequilibrada dos conteúdos disciplinares específicos do conhecimento científico em comparação ao conhecimento pedagógico. Ainda segundo os autores, os estudantes resistem em aceitar que além de aprender o conteúdo, é preciso aprender a ensiná-lo. Um reflexo disto é o que resulta em implicações como as descritas por Mourão e Ghedin (2019) sobre a persistência dos problemas na formação de professores de ciências da natureza, com enormes fragilidades em ensinar os conteúdos básicos de suas áreas de conhecimento, mesmo com a disponibilização de disciplinas de prática de ensino, estágios, metodologias ofertadas nas graduações.

Neste esteio, o ato reflexivo sobre a formação inicial e os aspectos elementares do trabalho docente são necessários na graduação. Dos discursos apresentados, percebemos a relevância das reflexões sobre o papel das disciplinas pedagógicas para a formação docente, do planejamento e de outros desafios a serem superados. Isso se deve inicialmente a uma conscientização de que o curso de licenciatura está formando profissionais para atuarem como professores, essa é uma chave importante. Após isso mais consolidado, o estudante começa a ter interesse em se aprofundar na sua própria formação profissional, considerando todos os saberes envolvidos no professorado.

Vale ressaltar que para aprender o conteúdo e como ensiná-lo, corriqueiramente o licenciando se depara com o que foi relatado na acolhida 02: “A gente acha que por saber os conceitos básicos vai conseguir ter o controle de uma turma, ao passo que os dias vão passando e os conteúdos vão aparecendo e você percebe que não é tão bom assim.” Santana e Ribeiro (2021) falam que na atualidade, os estudantes que chegam a esse nível de ensino, especialmente os ingressantes dos cursos de licenciatura em Química, Física e Matemática, por vezes não dominam o conhecimento prévio e não estão habituados ao exercício do raciocínio lógico e as abstrações indispensáveis ao aprofundamento dos conteúdos específicos de cada área de conhecimento.

Por outro lado, ainda no relato da acolhida 02, o estudante também revela: “O aluno, agora com a visão de professor, vai tentar adquirir uma postura que ele ainda não tem, pois nós não temos essa postura de professores, somos estudantes com o mínimo de conhecimento para já estar exercendo a profissão. ” É comum encontrarmos estudantes já exercendo a profissão, as consequências deste comportamento na formação inicial são variadas, podemos destacar alguns impactos, tais como: o estudante achar que não precisa fazer aquelas disciplinas de didática porque ensinar é fácil, ou então pensar que o fato de já atuar como professor já sabe tudo que precisa, bem como imaginar que basta fazer como aquele professor que ele gostava 
tanto. Logo, o modelo reprodutivo continua a se consolidar, pautado numa prática pedagógica irrefletida.

As mudanças necessárias para uma formação inicial de professores de Química mais consistente são inúmeras, mas uma importante ferramenta é a disponibilidade de espaços para diálogos acerca do trabalho docente, especialmente em contextos específicos da área de conhecimento. Um exemplo disso é verificado na acolhida 07, onde foram tratados aspectos intrínsecos do planejamento didático de aulas experimentais e os entraves para a concretização dessa estratégia nas escolas. Esse contexto é muito peculiar dos professores de ciências da natureza e precisa ser conversado, discutido, amadurecido. Percebemos que a acolhida com textos direcionados as vivências dos professores de química proporcionaram reflexões, ao ponto de fazer o aluno se transportar para aquela realidade e buscar alternativas para solucionar possíveis problemas.

Os espaços de diálogos estão envolvidos na percepção do professor formador sobre as necessidades da sua turma, não apenas no que diz respeito a conteúdo. A acolhida 05 foi realizada diante dos impactos emocionais dos acontecimentos da pandemia na classe, a afetividade e a compreensão com aquele momento foram essenciais para a continuidade dos estudantes na disciplina, mesmo com tantos motivos para desistências. Essa interlocução deveria acontecer em todas as disciplinas de um modo natural, no entanto, segundo Gonçalves e Fernandes (2010), os licenciandos reconhecem estes espaços nas componentes curriculares de Prática de Ensino.

Um estudo de demonstrou que os estudantes esperam dos professores um ambiente favorável à aprendizagem, por meio da relação interpessoal. Nessa direção, o autor ressalta que a aproximação não contenha tantos formalismos (Ribeiro, 2020). Ademais, a relação educativa é social e o funcionamento dessa relação depende de como a comunicação ocorre entre docentes e discentes. A interação em sala de aula é dialógica entre os sujeitos que fazem o fenômeno educativo acontecer, portanto ambos são responsáveis e possibilitam o ensino e a aprendizagem (Santana \& Ribeiro, 2021).

A formação de professores de ciências exatas possui muitos entraves, os quais precisam ser superados. Embora se atribua certo status a essa área, as investigações voltadas ao diálogo, a afetividade e a troca de experiências na formação de docentes dessas áreas vão na contramão deste prestígio (Santana \& Ribeiro, 2021). Um estudo analisou as características do que os estudantes classificam como bom professor, as quais podemos citar o modo como lida com o componente curricular, capacidade de escuta, a paciência, a compreensão e a condição de manter um bom relacionamento com os alunos. O mesmo estudo também revelou que os professores universitários agem de modo autoritário, rígido, com repreensões públicas e, por conseguinte, geram desistência dos componentes curriculares e, por vezes, do curso (Ribeiro, 2020).

Diante do exposto, pode-se considerar que as acolhidas utilizadas são meios facilitadores da aproximação entre professores e alunos, propiciam o diálogo leve, oportunizam ao professor formador conhecer a realidade dos estudantes. Neste esteio, os professores possuem mais elementos para planejar as atividades, correlacionando as necessidades formativas aos contextos dos alunos.

\section{Considerações Finais}

A partir do que foi apresentado no texto, percebe-se que o tema discutido na pesquisa, buscou proporcionar reflexões sobre os momentos de acolhida nas aulas de ensino superior, mais especificamente, a importância dos momentos de acolhida como potencial para diálogos reflexivos na disciplina de Práticas Educativas em um curso de química.

De acordo com o desenvolvimento do trabalho, ficou evidente as contribuições desses momentos como forma de ajudar na adaptação e permanência dos discentes nos cursos de licenciatura em Química. Devido ao caráter mais específico do conhecimento químico e as influências do currículo baseado na racionalidade técnica, esses cursos ainda não desenvolvem nas suas rotinas espaços para diálogos abertos, com trocas de experiências e com afetividade entre os pares, professor-aluno. 
Para tanto o presente estudo, conforme os depoimentos dos estudantes que participaram da pesquisa, elucida de maneira clara e objetiva, a satisfação dos discentes em participar dos momentos de acolhimento durante as aulas. Os relatos nos mostram o quanto os licenciandos se sentiram confortáveis e confiantes em compartilhar suas percepções sobre os temas que eram trabalhados nos momentos de acolhida. O bem estar, a afetividade, o carinho e a abertura para o diálogo, revelam a importância e o impacto positivos que as acolhidas trouxeram na vida acadêmica dos discentes.

Compreende-se ainda que os docentes possuem papel fundamental na condução de uma aula mais prazerosa e significativa. Nesse movimento, os educadores precisam dinamizar suas aulas facilitando o processo de construção de novos conhecimentos, pois, os cursos de nível superior em sua maioria, são considerados em sua essência, teóricos. Daí a importância de os docentes utilizarem estratégias aproximando teoria e prática, e nessa relação consiga concretizar a necessidade do conhecimento técnico agregado à natureza humana dos estudantes.

Desta forma, conclui-se com os resultados coletados e analisados, que o acolhimento nos espaços educacionais fortalece cada vez mais as relações estabelecidas entres estudantes e professores, e que os sentimentos surgidos nesses momentos traduzem o desejo de partilha que cada um/a sente ao dialogar com todos que vivenciam o processo. Este estudo amplia a nossa percepção sobre a necessidade de realização de mais pesquisas abordando as relações educativas na formação inicial de professores de Química, ampliando para as outras ciências exatas. A compreensão mais aprofundada dos impactos dessa abordagem na qualidade dos profissionais formados, ainda traz como perspectivas, a investigação destes elementos na formação continuada e na prática pedagógicas destes professores nas escolas.

\section{Agradecimentos}

Aos discentes sujeitos participantes da pesquisa. Ao Instituto Federal do Ceará e a Universidade da Integração Internacional da Lusofonia Afro-Brasileira.

\section{Referências}

Conselho Nacional de Educação. (2019). Diretrizes Curriculares Nacionais para a Formação Inicial de Professores para a Educação Básica. https://apoiocoordenadoriascursosgraduacao.paginas.ufsc.br/files/2020/01/Resolução-CNE_CP-2_20dez2019.pdf.

Coulon, A. A. (2008). Condição de Estudante: a entrada na vida universitária. Salvador: EDUFBA.

Freire, P. (1979). Educação e mudança. 12 ${ }^{\mathrm{a}}$ Ed. Rio de Janeiro: Paz e Terra.

Freire, P. (2011). Pedagogia da autonomia: saberes necessários à prática educativa. São Paulo: Paz e Terra.

Goergen, P. (2016). Formação humana hoje: História e atualidade. In: Rajobac, R., Bombassaro, L. C. \& Goerge, P. (Eds.). Experiência formativa e reflexão. Caxias do Sul: EdICES.

Gonçalves, F. P. \& Fernandes, C. S. (2010). Narrativas acerca da prática de ensino de Química: um diálogo na formação inicial de professores. Química Nova na Escola, 32(2), 120-127.

Guimarães, S. E. R. \& Boruchovitch, E. (2004). O estilo motivacional do professor e a motivação intrínseca dos estudantes: uma perspectiva da Teoria da Autodeterminação. Psicologia, Reflexão e Crítica, 17(2), 143-150.

Larrosa, J. (2002). Notas sobre a experiência e o saber da experiência. Trad. João Wanderley Geraldi. In: Revista Brasileira de Educação.

Maldaner, O. A. (2008) A Pós-Graduação e a formação do educador químico. In: ROSA, M. I. P.; ROSSI, A. V. (Orgs.). Educação Química no Brasil: memórias, políticas e tendências. Campinas: Editora Átomo.

Minayo, M. C. S. (Org.). (2001). Pesquisa social: teoria, método e criatividade. Petrópolis: Vozes.

Mourão, I. C. \& Ghedin, E. (2019). Formação do professor de Química no Brasil: a lógica curricular. Educação em Perspectiva, $10,1-16$.

Oliveira, T. A. L., Alves, F. I. M., Almeida, M. P., Domingues, F. A. \& Oliveira, A. L. (2017) Formação de professores em foco: uma análise curricular de um curso de Licenciatura em Química. ACTIO: Docência em Ciências, 2(2), 137-158. 
Research, Society and Development, v. 111, n. 1, e10211124512, 2022 (CC BY 4.0) | ISSN 2525-3409 | DOI: http://dx.doi.org/10.33448/rsd-v11i1.24512

Prodanov, C. C. \& Freitas, E. C. (2013). Metodologia do Trabalho Científico: métodos e técnicas da pesquisa e do trabalho acadêmico. 2 Ed. Novo Hamburgo - RS: Universidade Feevale.

Quadros, A. L., Silva, A. S. F. \& Mortimer, E. F. (2018) Relações pedagógicas em aulas de ciências da educação superior, Química Nova, 41(2), 227-235.

Ribeiro, M. L. (2020) A relação professor-estudante na educação superior, Educação em Análise, 5(1), 185-200.

Rodrigues, N. (2001) Educação: da formação humana à construção do sujeito ético. Educação \& Sociedade, 22 (76), $232-257$.

Santana, C. C. \& Ribeiro, M. L. (2021) Representações sobre a relação educativa na prática docente de professores da área de ciências exatas. Revista Cocar, $15(33) 1-22$.

Teixeira, G. F. M., Bernini, G. M. C. \& Santos, P. P. (2018). A construção da professoralidade do docente universitário: os professores que atuam nas ciências exatas. IV EDIPE - Encontro Estadual de Didática e Prática de Ensino.

Tomaél, M. I., Alcará, A. R. \& Chiara, I. G. (2005). Das Redes Sociais à Inovação. Ciência da Informação, 34(2), 93-104.

Yin, R. K. (2015). Estudo de caso: planejamento e métodos. Tradução: Cristhian Matheus Herrera, 5. ed, Porto Alegre: Bookman. 